\title{
A time series analysis of permanent GNSS stations in the northwest network of Iran
}

\author{
Seyed Amin Ghasemi Khalkhali*,1, Alireza A. Ardalan ${ }^{1}$, Roohollah Karimi ${ }^{2}$ \\ (1) School of Surveying and Geospatial Engineering, College of Engineering, University of Tehran, Tehran 11155-4563, Iran \\ (2) Department of Geodesy and Surveying Engineering, Tafresh University, Tafresh 39518-79611, Iran
}

Article history: received March 25, 2020; accepted March 24, 2021

\begin{abstract}
The aim of this study is to estimate reliable velocities along with their realistic uncertainties based on a robust time series analysis including analysis of deterministic and stochastic (noise) models. In the deterministic model analysis part, we use a complete station motion model comprised of jump effects, linear and nonlinear trend, periodic components, and post-seismic deformation model. This part also consists of jump detection, outlier detection, and statistical significance of jumps. We perform the deterministic model analysis in an iterative process to elevate its efficiency. In the noise analysis part, first, we remove the spatial correlation of observations using the weighted stacking method based on the common mode error (CME) parameter. Next, a combination of white and flicker noises is used to determine the stochastic model. This time series analysis is applied for 11-year time series of 25 permanent GNSS stations from 2006 to 2016 in the northwest network of Iran. We reveal that there is a nonlinear trend in some stations, although most stations have a linear trend. In addition, we found that a combination of logarithmic and exponential functions is the most appropriate post-seismic deformation model in our study region. The result of the noise analysis shows that the spatial filtering reduces the norm of post-fit residual vector by $19.34 \%, 17.51 \%$, and $12.44 \%$ on average for the east, north, and up components, respectively. Furthermore, the uncertainties obtained from the combination of white and flicker noises at the east, north, and up components are 5.0, 4.8 , and 4.4 times greater than those of the white noise model, respectively. The results indicate that the stations move horizontally with an average velocity of $36.0 \pm 0.3 \mathrm{~mm} / \mathrm{yr}$ in the azimuth of $52.66^{\circ} \mathrm{NE}$ which is compatible with velocities obtained from MIDAS. We obtained the vertical velocity of most stations in the range of -5 to $5 \mathrm{~mm} / \mathrm{yr}$. However, in three stations of GGSH, ORYH, and BNAB, which are in the proximity of Lake Urmia, the vertical velocities are estimated to be $-80.9 \mathrm{~mm} / \mathrm{yr},-50.6 \mathrm{~mm} / \mathrm{yr}$, and $-11.4 \mathrm{~mm} / \mathrm{yr}$, respectively. Moreover, we found that these three stations possess large periodic signal amplitudes in all three coordinate components as well as a nonlinear trend in the up component.
\end{abstract}

Keywords: Time series analysis; GNSS permanent station; Northwest network of Iran; Spatial filtering; Post-seismic deformation model. 


\section{Seyed Amin Ghasemi Khalkhali et al.}

\section{Introduction}

Development of Global Navigation Satellite Systems (GNSSs) such as GPS, GLONASS, and BeiDou have provided a rich source of spatial dataset with global coverage. Position time series of permanently operating ground stations have many applications among which the monitoring of the movement of the Earth's crust is the most important. In addition, the time series can be used to study crustal deformation, plate tectonic motions [e.g., Kogan and Steblov, 2008; Tobita, 2016; Graham et al., 2018], seismic processes [e.g., Burgmann et al., 2002; Williams, 2003b], postglacial rebounds [e.g., Larson and van Dam, 2000; Nocquet et al., 2005; Sella et al., 2007; Argus et al., 2014; Bogusz et al., 2019], land uplift rates [e.g., Ostanciaux et al., 2012; Bogusz et al., 2019], and national terrestrial reference frames realization [e.g., Bevis and Brown, 2014].

To achieve reliable results in the aforementioned applications, a detailed time series analysis is required. The time series analysis includes the analysis of deterministic and stochastic (noise) models. In the deterministic model analysis, the aim is to determine the optimal functional model for the station motion. This motion model is comprised of four main parts: trend, jumps, periodic components, and post-seismic deformation model. Although most studies consider a linear trend, in some areas such as active ice sheets or active volcanoes a nonlinear trend may be more appropriate than a linear one [Bevis and Brown, 2014]. Another effective parameter in the motion model is the jump effect. The main sources of the jump are instrument source due to equipment changes and seismic source due to strong earthquakes [Wdowinski et al., 1997; Williams, 2003b; Williams et al., 2004; Gazeaux et al., 2013; Bruni et al., 2014; Bevis and Brown, 2014; Amiri-Simkooei et al., 2019]. If the jumps are not taken into account in the time series analysis, the parameters of the station motion model, such as the velocity of the stations, will be biased [Williams, 2003b; Bruni et al., 2014; Montillet et al., 2015].

Regarding the periodic part of the motion model, it is worth mentioning that the main periodic components observed in the GNSS time series are annual and semi-annual periodic signals [Blewitt and Lavallee, 2002; Dong et al., 2002; Klos et al., 2018; Jiang et al., 2018], the GPS draconitic year period with the length of about 351.4 days and its higher harmonics, i.e., $351.4 / n, n=1,2,3, \ldots$, [Amiri-Simkooei et al., 2007; Ray et al., 2008; King and Watson, 2010; Santamaria-Gomez et al., 2011; Wang et al., 2012; Amiri-Simkooei, 2013; Bogusz and Klos, 2016; Allahverdi-zadeh et al., 2016; Amiri-Simkooei et al., 2017], the period of Chandler wobble with the length of about 432 days [Bogusz and Klos, 2016; Bogusz et al., 2016; Amiri-Simkooei et al., 2017; Klos et al., 2018], the quarterly period [Bogusz and Klos, 2016], and the period of about 122 days [Amiri-Simkooei et al. 2017].

To complete the motion model, a post-seismic deformation model should also be taken into account to model the post-seismic deformation. A seismic cycle can be divided into three parts including inter-seismic slip, co-seismic slip, and post-seismic slip. A seismic jump is a co-seismic slip and its following motion is a post-seismic slip. To model a post-seismic decay motion, exponential function [Nikolaidis, 2004], logarithmic function [Bevis and Brown, 2014; Itoh and Nishimura, 2016; Wu et al., 2019] or a combination of them [Tobita, 2016; Klos et al., 2019] can be used.

In the noise analysis, the aim is to determine an optimal stochastic model for estimating realistic uncertainties. For this purpose, the spatial [Wdowinski et al., 1997; Nikolaidis, 2004] and temporal [Langbein and Johnson, 1997; Zhang et al., 1997; Mao et al., 1999; Williams, 2003a; Langbein, 2004; Williams et al. 2004] correlations of GNSS position time series are investigated. Two usual methods to study the spatial correlation are the stacking method [Wdowinski et al., 1997; Nikolaidis, 2004; Marquez-Azua and De Mets, 2003; Wdowinski et al., 2004; Wang et al., 2012; Jiang et al., 2018] and the Empirical Orthogonal Function (EOF) method [Teferle et al., 2008]. In the branch of the EOF method, the Principal Component Analysis (PCA) method [Dong et al., 2006; He et al., 2015; Liu et al., 2015; Borghi et al., 2016; Gruszczynski et al., 2018; Birhanu et al., 2018; Wu et al., 2019; Tan et al., 2020] and the Karhunen-Loeve Expansion (KLE) method [Dong et al., 2006] can be mentioned. In the stacking method, the Common Mode Error (CME) parameter is calculated to remove the spatial correlation between the stations. This error is caused by uncorrected environmental loading effects, GPS satellite orbit biases, systems errors, and other unmodeled residual errors [He et al., 2015].

The temporal correlation is studied in both frequency and time domains. The methods on the frequency domain are the ones that require the definition of the power spectrum, as the methods based on the power-law process, whereas the methods based on the time domain find the temporal correlation between data using such as autocovariance and auto-correlation function [King et al., 1995; Zhang et al., 1997; Hackl et al., 2011; Borghi et al., 2016; Barzaghi and Borghi, 2018]. In the frequency domain, the Maximum Likelihood Estimation (MLE) method [Langbein and Johnson, 1997; Zhang et al., 1997; Mao et al., 1999; Williams, 2003a; Williams et al., 2004; 
Langbein, 2004; Teferle et al., 2008; Langbein, 2008; Santamaria-Gomez et al., 2011; Wang et al., 2012] and the Variance Component Estimation (VCE) method [Amiri-Simkooei et al., 2007; Amiri-Simkooei, 2009; AmiriSimkooei, 2016] are commonly applied. Similar to most geophysical phenomena, the noise in the GNSS time series is represented via power spectrum relation as follows [e.g., Agnew, 1992; Mao et al., 1999; Williams, 2003a; Williams et al., 2004; Santamaria-Gomez et al., 2011]:

$$
P_{y}(f)=P_{0}\left(\frac{f}{f_{0}}\right)^{k}
$$

where $f$ is the temporal frequency, $P_{0}$ and $f_{0}$ are normalized constants, and $k$ is the spectral index [Agnew, 1992]. The spectral index, $k$, usually varies from -3 to 1 , where $k=0$ and $k \neq 0$ represent the white and power-law (colored) noises, respectively. In the special cases, the integer spectral indices $k=-1$ and $k=-2$ indicate the flicker and random walk noises, respectively [Williams et al., 2004; Santamaria-Gomez et al., 2011]. While the white noise implies the total independence, a power-law noise shows a temporal correlation between the data.

According to Zhang et al. [1997], Williams et al. [2004], Teferle et al. [2008], Santamaria-Gomez et al. [2011], Bogusz and Kontny [2011], Wang et al. [2012] and Klos et al. [2018], the power-law noise considerably affects the velocity uncertainties. This is while the use of a pure white noise model would lead to an underestimation of the uncertainties (optimistic uncertainties). The definition of an optimal stochastic model substitutes optimistic values of uncertainties with realistic ones.

The main purpose of this study is to implement a robust time series analysis to estimate the reliable velocities and their realistic uncertainties of the permanent stations located at the northwest of Iran. Prior to this work, several studies have been conducted to estimate the velocity field and crustal deformation based on the GNSS observations in Iran [e.g., Nilforoushan et al. 2003; Vernant et al. 2004; Masson et al. 2007; Khorrami et al., 2019], and especially in its northwestern area [e.g., Masson et al. 2006; Djamour et al., 2011; Rizza et al., 2013]. It is important to note that no time series analysis has been implemented in these studies. Moreover, most of them are either based on the permanent observations with a short time span or the campaign observations. Here, in contrast to previous studies, a complete time series analysis is performed to estimate velocities and their uncertainties. We utilize 11-year (a long time span) observations of permanent GNSS stations from 2006 to 2016. We attempt to achieve the optimal station motion model in the study area by determining the nonlinear trend and post-seismic deformation models. In the next section, input data used in this study are introduced. Time series analysis is described in details in Sect. 3. Numerical results are given in Sect. 4. Finally, conclusions are presented in Sect. 5 .

\section{Data}

In this study, we use daily position time series of 11-year GPS observations at 25 permanent stations in the northwest network of Iran (Figure 1) in the time span from 2006 to 2016. These stations are a part of the Iranian Permanent GPS Network (IPGN). The IPGN consists of 133 permanent GPS stations established by the National Cartographic Center (NCC) of Iran since 2005 (Figure 2). Due to population distribution, seismicity, and distribution of active faults, in three parts of Iran namely the Tehran network in the central Alborz area, the Khorasan network in the northeast of Iran, and the Azerbaijan network in the northwest of Iran, the IPGN stations are denser than the other parts (Figure 2).

To produce the time series, the GPS observations with the intervals of 30 seconds have been processed by the NCC using GAMIT/GLOBK 10.6 software package [Herring et al., 2015] in the International Terrestrial Reference Frame 2014 (ITRF2014) [Altamimi et al., 2016]. It should be mentioned that the observations stored at 23 International GNSS Service (IGS) stations, shown in Figure 3, have also been used in the processing. The daily time series of station positions consists of the east, north, and up components along with their standard deviations.

To investigate earthquake effects on the station motion, earthquake data in the northwestern area of Iran and its surrounding are used. These data have been collected by the Iranian Seismological Center (IRSC), which are available from http://irsc.ut.ac.ir. According to the earthquake data, 19 earthquakes with the magnitude of higher than 5 have occurred in the study region during 2006-2016 (Figure 4). 
Seyed Amin Ghasemi Khalkhali et al.

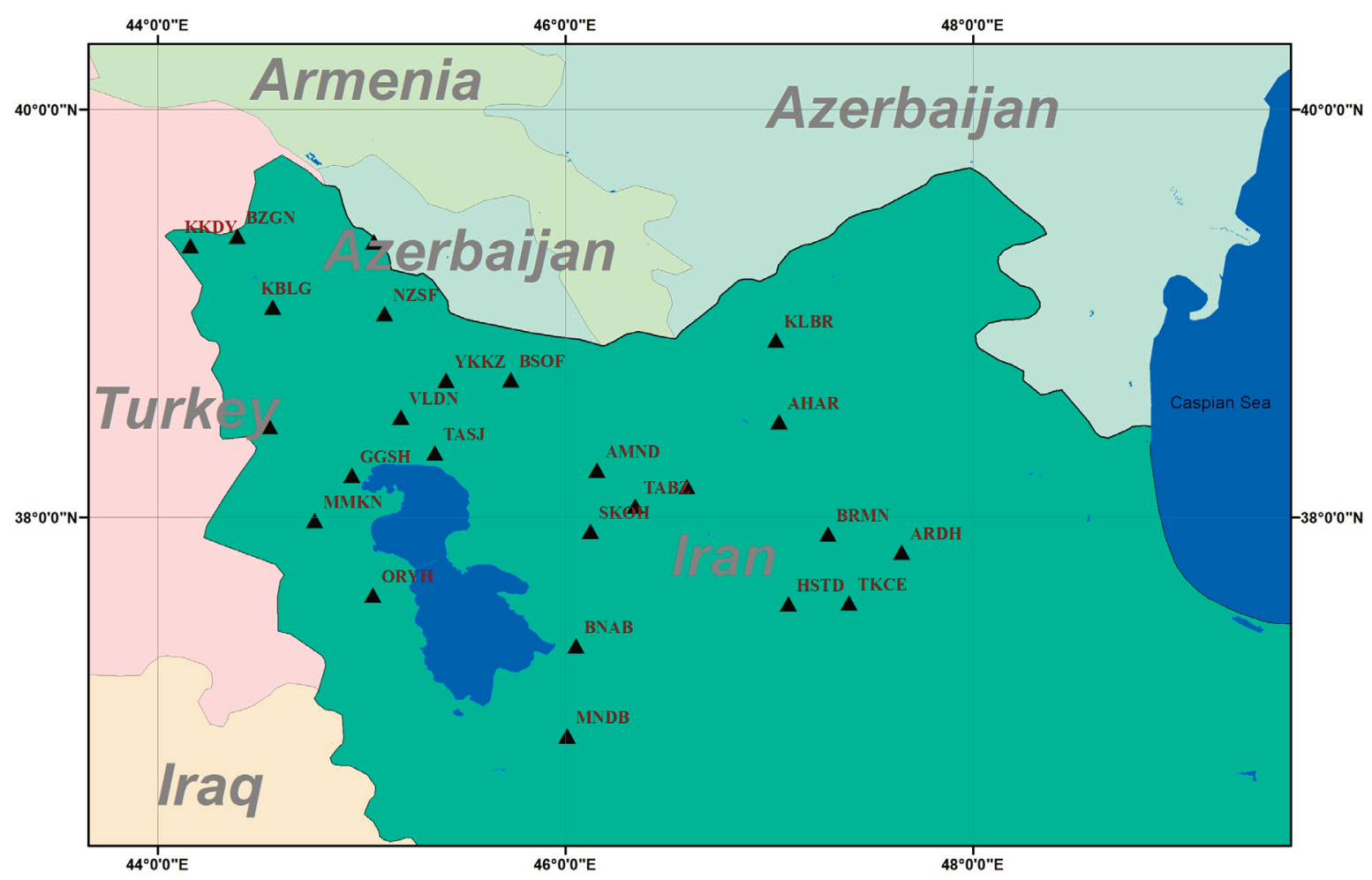

Figure 1. The location of stations in the northwest network of Iran.

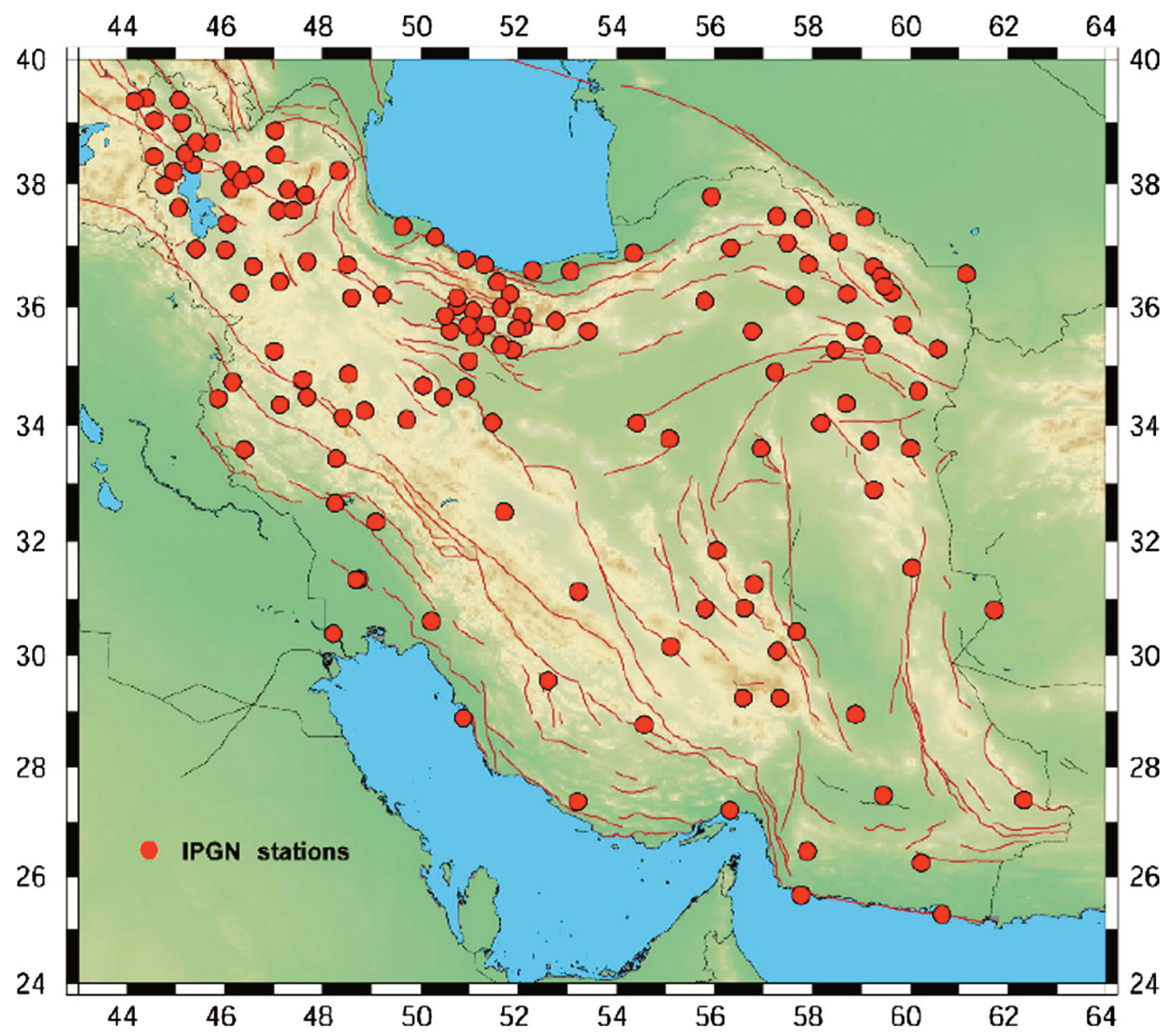

Figure 2. The location of IPGN stations (http://ncc.org.ir). 
Time series analysis of GNSS stations

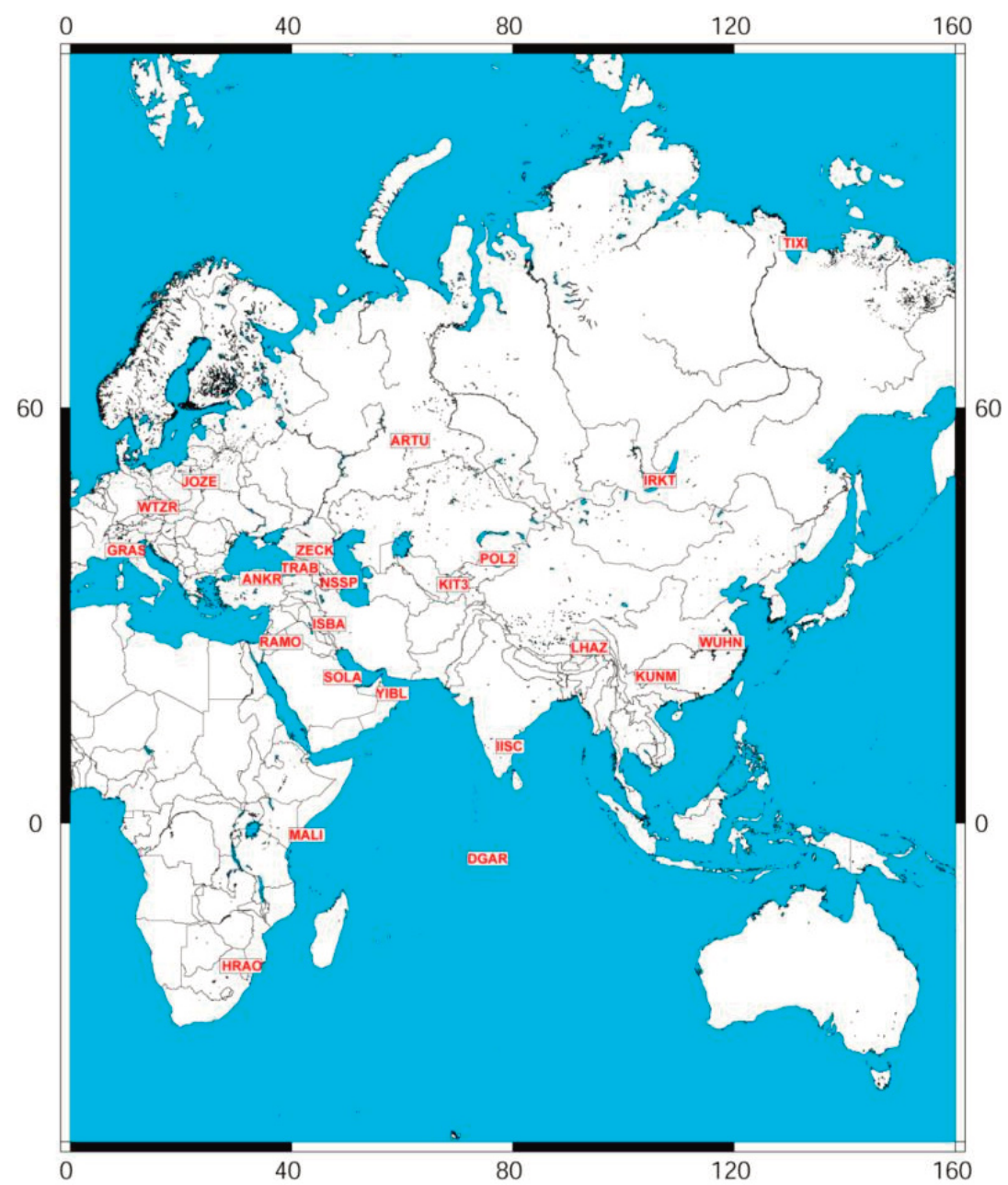

Figure 3. IGS stations used for GPS observation processing (http://ncc.org.ir).

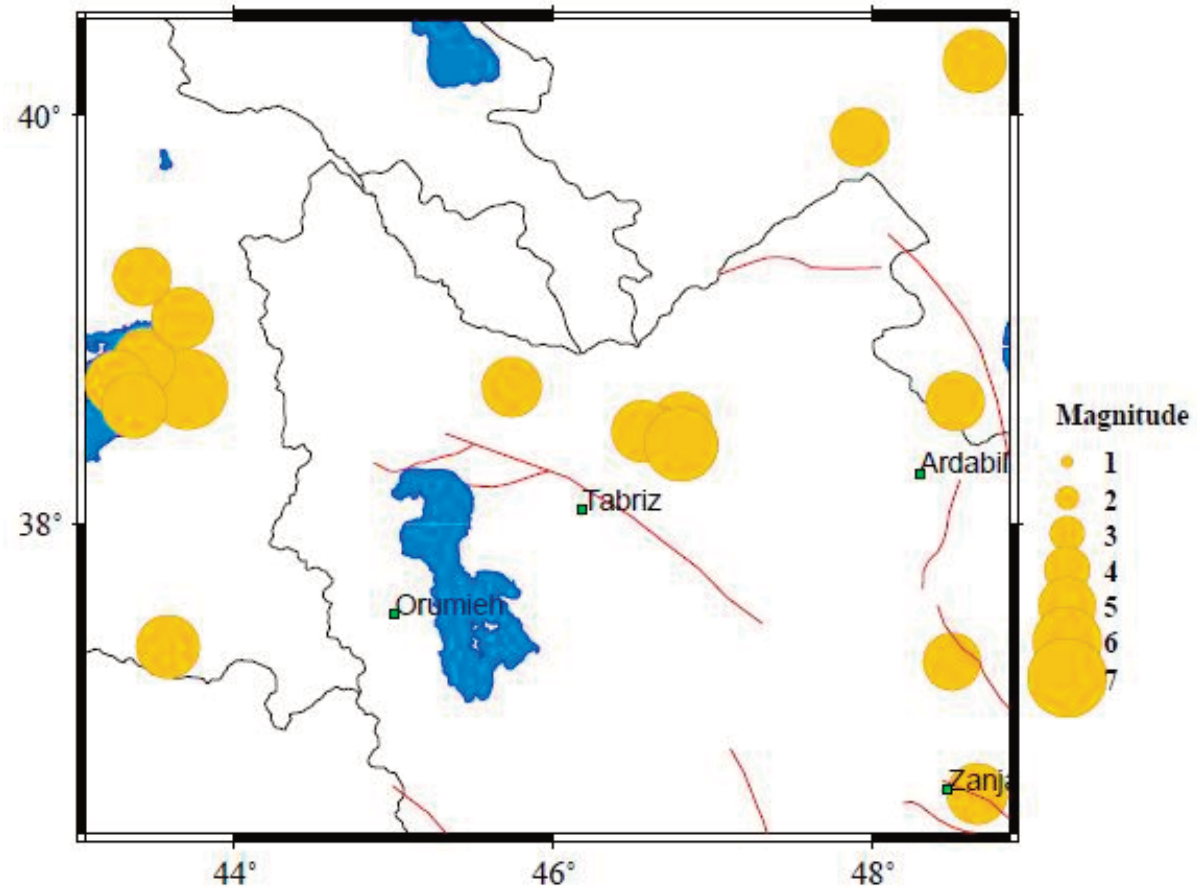

Figure 4. The distribution and magnitude of earthquakes with the magnitude of higher than 5 occurred in northwestern area of Iran and its surrounding (http://irsc.ut.ac.ir). 


\section{Seyed Amin Ghasemi Khalkhali et al.}

\section{Time series analysis}

As mentioned earlier, the time series analysis is performed in two parts: deterministic model analysis and noise analysis. In the section, we describe our methodology for these parts in detail.

\subsection{Deterministic model analysis}

\subsubsection{Jump detection}

One of the important parameters affecting the analysis of the GNSS time series is the jump in the data [Borghi et al., 2012]. If the time of equipment change and earthquake is known, then the epoch of jump occurrence is known. In addition, the jumps can be detected using visual (manual) and mathematical (automated) methods [Goudarzi et al., 2013; Gazeaux et al., 2013]. In our case, there is no a-priori information regarding stations. Hence, we detect all jumps using the mathematical methods.

Most mathematical methods relying on comparing the mean values obtained from two adjacent windows that move on the time series data [Riley, 2008; Montillet et al., 2015]. In this study, for three components (east, north, and up) in each epoch, two 90-day windows including the previous and next data of that epoch are considered. Next, a separate linear model is fitted to each window via the weighted least-squares (WLS) method. Using these linear models, two values for each component are computed at the mentioned epoch. These computational values are compared with the observed value at the mentioned epoch and their maximum difference is calculated. If this difference is more than three times the standard deviation of data, the epoch is considered as a jump candidate. It should be noted that in the epochs which are close to the beginning or end of time series, the length of the 90-day intervals is reduced to the available epochs. Consequently, neglecting the source of jump occurrence, the jumps are detected using the developed method.

\subsubsection{The station motion model}

After detecting the jump epochs, the station motion model at the time $t$ for each component, like $y$ component, can be written as follows:

$$
\begin{aligned}
& y(t)=y_{0}+v_{y} t+\text { nonlinear trend }+\sum_{j=1}^{n j} g_{j} H\left(t-t_{g_{j}}\right)+\sum_{P=1}^{n p}\left[s_{p} \sin \left(w_{P} t\right)+c_{P} \cos \left(w_{P} t\right)\right] \\
& + \text { post-seismic deformation }+r(t)
\end{aligned}
$$

where $y_{0}$ is the initial value, $v_{y}$ is the velocity, $H\left(t-t_{g_{j}}\right)$ is the Heaviside step function, $n_{j}$ is the number of jumps with the magnitudes $g_{j}$ occurring at epochs $t_{g_{j}}$, the coefficients of $s_{p}$ and $c_{p}$ describe the $p$ th periodic signal with the angular velocity $w_{P}$, and $r$ denotes the residuals or noise.

The first two terms of Eq. (2) indicate the linear trend of station motion with a constant velocity. In this study, we also consider a nonlinear trend in the motion model (third term). For this purpose, various nonlinear functions such as polynomials, exponential, and logarithmic functions, as well as their various combinations are investigated to obtain the most appropriate function. The fourth term represents the jump effect, where the number of jumps, $n_{j}$, and their occurrence time, $t_{g_{j}}$, are determined in the jump detection step. Note that the magnitude of jumps, $g_{j}$, is unknown. Two strategies can be adopted to consider the jump effect in Eq. (2). In the first strategy, called 1component method, the detected jumps of each component are considered only for the motion model of the same component [Bruni et al., 2014], while in the second method, called 3-component method, the detected jumps of each component are also considered for the motion models of the other two component [Gazeaux et al., 2013].

The fifth term demonstrates the periodic part of time series. Although as mentioned earlier, there are many signals in GNSS time series, we consider four main periodic components namely annual, semi-annual, draconitic year (351.4 days), and second draconitic harmonic (175.7 days). The reason for this is that the temporal correlation in the time series is strictly correlated to the functional model, and the spectral index, $k$, decreases when more 
periodic signals are introduced [Amiri-Simkooei et al. 2007; Davis et al. 2012; Bogusz and Klos, 2016; Barzaghi and Borghi, 2018].

To model the post-seismic deformation in Eq. (2), we investigate three various models to find the best postseismic deformation model [Altamimi et al., 2016; Klos et al., 2019]. These models are defined as follows:

$$
\begin{gathered}
\text { Model 1: }+\sum_{E=1}^{n_{E}} A_{E} \log \left(1+\frac{\Delta t}{\mathrm{~T}_{\log }}\right) \\
\text { Model 2: }+\sum_{E=1}^{n_{E}} B_{E}\left(1-\exp \left(-\frac{\Delta t}{T_{\exp }}\right)\right) \\
\text { Model 3: }+\sum_{E=1}^{n_{E}} A_{E} \log \left(1+\frac{\Delta t}{T_{\log }}\right)+B_{E}\left(1-\exp \left(-\frac{\Delta t}{T_{\exp }}\right)\right)
\end{gathered}
$$

where $A_{E}$ and $B_{E}$ are the magnitudes of logarithmic and exponential functions, respectively, $n_{E}$ is the number of influential earthquakes on each station, and, $T_{\log }$ and $T_{\exp }$ are decaying time constants. $\Delta_{t}$ is the elapsed time after the earthquake which is defined as:

$$
\begin{array}{ll}
\Delta_{t}=t-t_{E Q} & \text { for } t>t_{E Q} \\
\Delta_{t}=0 & \text { for } t \leq t_{E Q}
\end{array}
$$

where $t_{E Q}$ is the earthquake epoch. There is a subtlety here in that determination of decaying time constants $T_{\log }$ and $T_{\text {exp }}$ are significant when trying to estimate only the post-seismic deformation function. Nevertheless, according to Bevis and Brown [2014], if this function is applied as a part of the station motion model in Eq. (2), then the results will not be sensitive to these parameters and the unknowns will well be estimated by considering the constant values for them.

\subsubsection{The outlier detection}

There are many methods to detect the outliers, which most of them are based on the post-fit residuals $\hat{\mathbf{r}}$ [Wdowinski et al., 1997; Nikolaidis, 2004; Yuan et al., 2007; Bogusz et al., 2015; Bogusz and Klos, 2016; Bogusz et al., 2016; He et al., 2017; Bogusz et al., 2019]. In this paper, we use the statistical index of the median as the central tendency and the statistical index of the interquartile range (IQR) as the dispersion [Riley, 2008; He et al., 2017; Bogusz et al., 2019].

The equation for the outlier detection is as follows [e.g., Nikolaidis, 2004]:

$$
-k<\frac{\hat{\mathbf{r}}-\operatorname{median}\left(\hat{\mathbf{r}}_{i+L}\right)}{I Q R}<k
$$

where $L$ is the length of intervals before and after each epoch and $k$ is the coefficient of IQR which is considered equal to 3 in this study [Bogusz et al., 2019]. For each epoch, these indices are calculated based on a one-year moving window where the epoch of interest is located at the center of the window (i.e., $L=6$ month).

\subsubsection{Iterative process}

Since the jumps and outliers affect each other, the deterministic model analysis calculations are accomplished in an iterative process. At each stage of the iteration, our calculations are: jump detection, estimation of the unknown parameters of station motion model using the WLS method, outlier detection, and inference test to identify statistically significative jumps. 


\section{Seyed Amin Ghasemi Khalkhali et al.}

In the last step of the above calculations, a statistical significance test is used to recognize real jumps [Borghi et al., 2009]. After determining the unknown parameters such as the magnitude of $j$ th jump for east, north, and up components $\left(g_{j_{E^{\prime}}} g_{j N}, g_{j U}\right)$, a jump vector at epoch $t_{g_{j^{\prime}}}$ is defined as follows:

$$
\mathbf{g}_{j}=\left(g_{j_{E^{\prime}}}, g_{j N}, g_{j U}\right)
$$

We use the statistic $z_{j}=\frac{g_{j}}{\sigma_{g}}$, where $g_{j}$ and $\sigma_{g_{j}}$ are norm of jump vector and its standard deviation, respectively. If obtained statistic is larger than the critical value of normal distribution at the $95 \%$ level of statistical significance, the intended jump is real.

The iterative process is terminated when no outlier is detected in the post-fit residuals. After the iterative process, by considering the effects of post-seismic deformations for seismic jumps, the total station motion model is formed. As a result, the unknown parameters, the post-fit residual vector $\hat{\mathbf{r}}$ and its covariance matrix $\mathbf{C}_{\hat{\mathbf{r}}}$ are obtained from the WLS method and based on the covariance matrix of the white noise.

\subsection{Noise analysis}

\subsubsection{Spatial filtering}

After determining all the parts of the total station motion model and calculating the post-fit residuals and their standard deviations, the spatial correlation between the data is calculated using the CME parameter. The stacking technique is appropriate for small-scale regions and cannot be applied to large-scale networks [Mao et al., 1999]. In a GPS network containing stations with distances shorter than $500 \mathrm{~km}$, where the CME parameter is evenly distributed over the region, Jiang et al., [2018] used the regional stack filtering method. Zhu et al. [2017] introduced the correlation weighted stacking filtering method for medium- and large-scale networks and applied it for CMONOC.

He et al. [2017] indicated that the fundamental assumption for the spatial filtering in regional networks is that the CME parameter is uniformly distributed over the region. In regional GPS networks, the CME uniformity or nonuniformity depends upon the network size and the environmental effects of the stations [e.g., Bogusz et al. 2015; He et al., 2015; Gruszczynski et al. 2016; He et al. 2017].

To calculate the CME parameter, a number of stations should be selected. The various criteria for the station selection can be found in Nikolaidis [2004], Teferle et al. [2008], Wang et al. [2012], Bogusz et al. [2015], and Zhu et al. [2017]. The daily value of the CME parameter is calculated using the weighted average or the mathematical expectation of the post-fit residuals of selected stations as:

$$
\operatorname{CME}(t)=E\left(\hat{\mathbf{r}}_{t}\right)=\sum_{j=1}^{n_{j}} \hat{\mathbf{r}}_{j}(t) p\left(\hat{\mathbf{r}}_{j}(t)\right)
$$

where $E$ is mathematical expectation, $p\left(\hat{\mathbf{r}}_{j}\right)$ is the probability of the post-fit residual of station $j, n_{s}$ is the number of selected stations, and $\hat{\mathbf{r}}$ is the post-fit residual vector of selected stations at $t$ epoch. The probability of the postfit residual of station $j$ is calculated from:

$$
p\left(\hat{\mathbf{r}}_{j}(t)\right)=\frac{\frac{1}{\sigma_{\hat{\mathbf{r}}_{j}}^{2}(t)}}{\sum_{j=1}^{n_{j}} \frac{1}{\sigma_{\hat{\mathbf{r}}_{j}}^{2}(t)}}
$$

where $\sigma^{2}$ is the variance of data. It is important to note that we need at least three stations without gap to estimate the CME parameter for each day. Otherwise, the CME parameter is considered equal to zero. Having the CME vector, the spatially filtered post-fit residual vector $\hat{\mathbf{r}}_{f}$ is obtained by removing the CME values from the $\hat{\mathbf{r}}$ vector as follows:

$$
\hat{\mathbf{r}}_{j}=\hat{\mathbf{r}}-\mathrm{CME}
$$

Hereby, $\hat{\mathbf{r}}_{j}$ is calculated for the three coordinate components of all stations. 


\subsubsection{Definition of the stochastic model}

In the MLE method, optimal noise model is obtained from maximizing the following function [Langbein and Johnson, 1997]:

$$
\left.\operatorname{MLE}\left(\hat{\mathbf{r}}_{f}, \mathbf{C}\right)=\frac{1}{(2 \pi)^{n / 2} \operatorname{det}(\mathbf{C})^{1 / 2}} \exp \left(-\frac{1}{2} t\right) \hat{\mathbf{r}}_{f}^{T} \mathbf{C}^{-1} \hat{\mathbf{r}}_{f}\right)
$$

where $\hat{\mathbf{r}}_{f}$ is the spatially filtered post-fit residual, $\mathbf{C}$ is the covariance matrix of the data, $n$ is the number of epochs, and det is the determinant operator. If the noise is assumed to be a combination of both white and power-law noises, the covariance matrix is calculated as [Williams et al., 2004]:

$$
\mathbf{C}=a^{2} \mathbf{I}+b_{k}^{2} \mathbf{J}_{k}
$$

where $a$ and $b_{k}$ are the white and power-law noise amplitudes, respectively, I is the $n \times n$ identity matrix, and $\mathbf{J}_{k}$ is the corresponding covariance matrix of the power-law noise with the spectral index $k$ [Williams et al., 2004]. Most studies dealing with GNSS time series have demonstrated that the optimal noise model is a combination of white and flicker noises [Zhang et al. 1997; Mao et al. 1999; Calais, 1999; Bock et al., 2000; Williams, 2003a; Williams et al. 2004; Langbein and Bock, 2004; Amiri-Simkooei et al. 2007; Teferle et al., 2008; Langbein, 2008; King and Williams, 2009; Santamaria-Gomez et al., 2011; Wang et al., 2012; Amiri-Simkooei, 2016; Bogusz et al., 2016; Birhanu et al., 2018; Li et al. 2019].

After calculating the covariance matrix of flicker noise [Zhang et al., 1997], the full covariance matrix of data including the unknown coefficients of $a$ and $b_{-1}$ as well as $\hat{\mathbf{r}}_{f}$ are substituted into Eq. (10). Finally, the MLE parameter and the unknown coefficients of $a$ and $b_{-1}$ are simultaneously determined using the downhill simplex method developed by Nelder and Mead [Press et al., 1992]. Finally, considering the full covariance matrix of data, all the unknowns of the total station motion model are estimated.

\section{Numerical results}

A summary of the time series used in this study is presented in Table 1 as well as the results of jump and outlier detection. To compare the 1-component method with the 3-component method, we utilized both two methods to estimate the velocities at all 25 stations. We found that the root mean square (RMS) of the differences in all three components is less than $1 \mathrm{~mm} / \mathrm{yr}(0.65 \mathrm{~mm} / \mathrm{yr}$ for the east component, $0.59 \mathrm{~mm} / \mathrm{yr}$ for the north component, and $0.73 \mathrm{~mm} / \mathrm{yr}$ for the up component). In this line, we found that if a jump occurs in only one component, the estimated jump magnitude $\left(g_{j}\right)$ in the other two components will be very small. In this work, the final results are presented based on the 3-component method. The reason for this is that, in the 1component method, the post-seismic deformation model is added to the motion model of the component where the seismic jump is detected. While the deformation model is observed in other components such that adding it to the station motion model reduces the norm of the residual vector.

Note that, after the statistical significance of jumps magnitude, about $46 \%$ of the detected jumps are discarded. From Table 1, we find that the maximum number of jumps is for the TABZ station (20 jumps) and the minimum number is for the GGSH station (1 jump). We find that each station has an average of 9 jumps in 11year observation. In addition, we find that the number of outliers detected for all the stations is about $4.4 \%$ of the total observations on average. As mentioned earlier, due to having more robust algorithms, the indices statistic of the median and IQR are preferred to the mean and standard deviation for the outlier detection.

Regarding the trend part of the motion model, we observed that most stations have a linear trend. However, we revealed a nonlinear trend in the secular station motion in the up component of GGSH, ORYH, and BNAB stations as well as the north component of MMKN station. Table 2 presents the functions that best fit the nonlinear trend of the four mentioned stations along with the percentage reduction of the norm of the residual vector. Note that in the case of a linear trend, the percentage reduction is zero. It is worth mentioning that although we investigated the logarithmic and exponential functions as well, these functions were not found to be appropriate. 
Seyed Amin Ghasemi Khalkhali et al.

\begin{tabular}{|c|c|c|c|c|c|c|c|c|c|}
\hline station & city & $\begin{array}{c}\text { latitude } \\
\text { (deg) }\end{array}$ & $\begin{array}{l}\text { longitude } \\
\text { (deg) }\end{array}$ & $\begin{array}{l}\text { start } \\
\text { date }\end{array}$ & $\begin{array}{l}\text { end } \\
\text { date }\end{array}$ & $\begin{array}{l}\text { number of } \\
\text { epochs without } \\
\text { observations } \\
\text { (day) }\end{array}$ & $\begin{array}{c}\text { number } \\
\text { of } \\
\text { jumps }\end{array}$ & $\begin{array}{c}\text { number } \\
\text { of } \\
\text { outliers }\end{array}$ & $\begin{array}{c}\text { number } \\
\text { of final } \\
\text { data }\end{array}$ \\
\hline AHAR & Ahar & 38.47 & 47.05 & 2006.00 & 2016.99 & 200 & 12 & 273 & 3545 \\
\hline AMND & Soufian & 38.23 & 46.16 & 2006.00 & 2016.99 & 132 & 8 & 135 & 3751 \\
\hline ARDH & Sarab & 37.83 & 47.65 & 2006.00 & 2016.99 & 325 & 9 & 377 & 3316 \\
\hline BNAB & Bonab & 37.37 & 46.05 & 2006.00 & 2016.99 & 197 & 16 & 92 & 3729 \\
\hline BRMN & Sarab & 37.92 & 47.29 & 2006.00 & 2016.99 & 178 & 7 & 196 & 3644 \\
\hline BSOF & Marand & 38.67 & 45.73 & 2006.00 & 2016.99 & 1005 & 4 & 82 & 2931 \\
\hline BZGN & Bazargan & 39.38 & 44.39 & 2006.60 & 2016.99 & 356 & 8 & 224 & 3438 \\
\hline GGSH & Salmas & 38.21 & 44.95 & 2006.00 & 2012.29 & 1892 & 1 & 9 & 2117 \\
\hline HSTD & Hashtrood & 37.58 & 47.09 & 2006.00 & 2016.93 & 361 & 8 & 94 & 3563 \\
\hline KBLG & Chaldoran & 39.03 & 44.56 & 2006.47 & 2016.99 & 305 & 13 & 177 & 3536 \\
\hline KHJE & Khaje & 38.15 & 46.60 & 2006.15 & 2016.99 & 356 & 7 & 81 & 3581 \\
\hline KKDY & Avajiq & 39.33 & 44.16 & 2006.60 & 2016.99 & 440 & 13 & 397 & 3181 \\
\hline KLBR & Kaleybar & 38.87 & 47.03 & 2006.00 & 2016.99 & 748 & 4 & 297 & 2973 \\
\hline MMKN & Mamaqan & 37.99 & 44.77 & 2006.27 & 2016.99 & 222 & 16 & 212 & 3584 \\
\hline MNDB & Miandoab & 36.93 & 46.01 & 2006.00 & 2016.99 & 847 & 15 & 103 & 3068 \\
\hline NZSF & Qarahziyaeddin & 39.00 & 45.11 & 2006.00 & 2016.99 & 162 & 9 & 88 & 3768 \\
\hline ORYH & Urmia & 37.62 & 45.06 & 2006.00 & 2016.99 & 201 & 12 & 151 & 3666 \\
\hline POLD & Poldasht & 39.35 & 45.06 & 2006.00 & 2016.99 & 361 & 8 & 107 & 3550 \\
\hline SKOH & Osku & 37.93 & 46.12 & 2006.00 & 2016.99 & 476 & 7 & 121 & 3421 \\
\hline TABZ & Tabriz & 38.06 & 46.34 & 2006.00 & 2016.99 & 105 & 20 & 153 & 3760 \\
\hline TASJ & Tasuj & 38.32 & 45.36 & 2006.00 & 2016.99 & 289 & 3 & 142 & 3587 \\
\hline TKCE & Turkman Chay & 37.58 & 47.39 & 2006.00 & 2016.99 & 239 & 7 & 61 & 3718 \\
\hline VLDN & Ivughli & 38.49 & 45.19 & 2006.32 & 2016.99 & 400 & 4 & 148 & 3470 \\
\hline YKKZ & Yekan-eKahriz & 38.67 & 45.41 & 2006.47 & 2016.99 & 419 & 6 & 88 & 3511 \\
\hline ZARI & Khoy & 38.45 & 44.55 & 2006.70 & 2016.99 & 445 & 9 & 150 & 3423 \\
\hline
\end{tabular}

Table 1. A summary of the 25 permanent GNSS stations in the northwest network of Iran

\begin{tabular}{cccccc} 
& & BNAB & GGSH & MMKN & ORYH \\
\hline \multirow{2}{*}{ E } & Trend function & Linear & Linear & Linear & Linear \\
\cline { 2 - 6 } & Percentage & $0 \%$ & $0 \%$ & $0 \%$ & $0 \%$ \\
\hline \multirow{2}{*}{$\mathrm{N}$} & \multirow{2}{*}{ Trend function } & Linear & Linear & $\begin{array}{c}\text { Third degree } \\
\text { polynomial }\end{array}$ & Linear \\
\cline { 2 - 6 } & Percentage & $0 \%$ & $0 \%$ & $23 \%$ & $0 \%$ \\
\hline \multirow{2}{*}{$\mathrm{U}$} & \multirow{2}{*}{ Trend function } & $\begin{array}{c}\text { Second degree } \\
\text { polynomial }\end{array}$ & $\begin{array}{c}\text { Third degree } \\
\text { polynomial }\end{array}$ & Linear & $\begin{array}{c}\text { Fifth degree } \\
\text { polynomial }\end{array}$ \\
\cline { 2 - 6 } & Percentage & $28 \%$ & $63 \%$ & $0 \%$ & $33 \%$ \\
\hline
\end{tabular}

Table 2. The functions used for modeling the nonlinear trend as well as the percentage reduction of the norm of the residual vector. 


\subsection{Post-seismic deformation model}

In order to be able to determine the post-seismic deformation model, it is required to discriminate seismic jumps from instrumental ones. For this purpose, if an earthquake with the magnitude of greater than $5 M_{w}$ occurs at the day of the jump occurrence in a radius of one degree around each station, that jump is considered a seismic jump. In our study area, two strong earthquakes have occurred: (1) the Ahar earthquake in the northwestern area of Iran with the magnitude of $6.5 M_{w}$ on August 11, 2012, and (2) the Van earthquake in Eastern Turkey with the magnitude of $7.1 M_{w}$ on October 23, 2011. The Van earthquake affects the BZGN and KKDY stations, and the Ahar earthquake affects the AHAR, BRMN, KHJE, and TABZ stations. Thus, the value of $n_{E}$ in Eq. (3) for the aforementioned stations is taken equal to one. For the values $T_{\log }$ and $T_{\exp }$ in Eq. (3), we consider three values of 6-month, one-year and two-year. We found that taking these different values for $T_{\log }$ and $T_{\exp }$ did not significantly affect the results, which is consistent with the findings of Bevis and Brown (2014). After evaluating Models 1, 2 and 3 given in Eq. (3), we concluded that the optimal model for the post-seismic deformation at all the six stations is a combination of logarithmic and exponential functions (Model 3).

\subsection{Spatial filtering}

The study area is considered as a small-scale network where the stacking method can properly be applied for its spatial filtering due to the following reasons: (1) the size of area is small, about $400 \mathrm{~km} \times 300 \mathrm{~km}$, (2) the average distance between the stations in this area is about $166 \mathrm{~km}$, (3) the longest distance in the network is about $420 \mathrm{~km}$, and (4) the average distance of the stations from the geometric center of the network is about $118 \mathrm{~km}$ where almost half of them are located less than $100 \mathrm{~km}$ from the center. Therefore, the whole network is considered as one block and the CME parameter is assumed to be uniform.

In this study, three scenarios are considered to select the stations for the calculation of the CME parameter. In the first scenario, we select the stations with fewer jumps, gaps, and outliers, and also not being affected by strong earthquakes. In the second scenario, we exclude the seismicity criterion, but consider the criteria of appropriate spatial distribution and widespread coverage over the whole region. In the third scenario, we apply the time series of the post-fit residuals at all the other stations to estimate the CME parameter at each station. For each scenario, we calculate the CME values for the three coordinate components of the stations and remove them from the unfiltered post-fit residual vector based on Eqs. (7), (8), and (9).

The most effective scenario is selected based on the reduction of the norm of post-fit residual vector before and after spatial filtering. The average values of the percentage reduction of the norm of post-fit residual vector for the three coordinate components after applying the three scenarios are given in Table 3. From Table 3, we find that the best scenario for the selection of stations is the third scenario. This may be due to being a small-scale network with the close stations to each other. As a result, we apply the weighted stacking method under the third scenario to perform the spatial filtering on the 25 stations of the network. The results show that the reduction percentages in the norm of post-fit residual vectors for the three east, north and up components are $19.34 \%, 17.51 \%$, and $12.44 \%$, respectively (Table 3). In accordance with the findings of previous studies [Tian and Shen 2014; Amiri-Simkooei et al. 2017; Li et al. 2019; Li et al. 2020], the east component is more affected by the CME parameter than the north and up components.

\begin{tabular}{rrcc} 
& east component & north component & up component \\
\hline scenario 1 & $13.54 \%$ & $10.67 \%$ & $12.12 \%$ \\
\hline scenario 2 & $15.52 \%$ & $14.02 \%$ & $11.93 \%$ \\
\hline scenario 3 & $19.34 \%$ & $17.51 \%$ & $12.44 \%$ \\
\hline
\end{tabular}

Table 3. The average relative reduction of the norm of post-fit residual vector for three scenarios. 


\section{Seyed Amin Ghasemi Khalkhali et al.}

\subsection{Velocity estimate}

Table 4 shows the amplitudes $a$ and $b_{-1}$ for the east, north, and up components as well as the reliable velocities and their realistic uncertainties at all stations. As expected, the amplitudes of the white and flicker noises are approximately the same for the horizontal components; the average value of $a$ is $0.6 \mathrm{~mm}$ and the average value of $b_{-1}$ is $2.2 \mathrm{~mm} / \mathrm{yr}^{1 / 4}$. From Table 4 , we find that the vertical component noise is significantly higher than those of the horizontal components by a factor of 3.7 for $a$ and a factor of 2.7 for $b_{-1}$. These results are consistent with the previously published results [Williams et al., 2004; Santamaria-Gomez et al., 2011; Amiri-Simkooei et al., 2017; Klos and Bogusez, 2017; Li et al., 2019]. The ratios of the average amplitudes of flicker noise to the average amplitudes of white noise at the east, north, and up components are 4.04, 4, and 2.68, respectively. This shows that the flicker noise amplitude is larger than the white noise amplitude at every three components. These results are also in line with the results of Teferle et al. (2008) showing that the power-law noise amplitude is about 3 to 4 times larger than the white noise amplitude.

\begin{tabular}{|c|c|c|c|c|c|c|c|c|c|}
\hline \multirow{2}{*}{ station } & \multicolumn{3}{|c|}{$a(m m)$} & \multicolumn{3}{|c|}{$b_{-1}\left(m m / y r^{1 / 4}\right)$} & \multicolumn{3}{|c|}{$v \pm \sigma_{v}(m m / y r)$} \\
\hline & east & north & up & east & north & up & east & north & up \\
\hline AHAR & 0.6 & 0.7 & 2.4 & 1.7 & 1.8 & 5.0 & $30.4 \pm 0.3$ & $20.3 \pm 0.3$ & $1.4 \pm 0.9$ \\
\hline AMND & 0.6 & 0.7 & 2.2 & 1.7 & 2.1 & 4.1 & $29.1 \pm 0.2$ & $21.0 \pm 0.2$ & $2.1 \pm 0.5$ \\
\hline ARDH & 0.6 & 0.8 & 2.7 & 2.1 & 2.3 & 5.9 & $27.6 \pm 0.3$ & $22.4 \pm 0.3$ & $0.7 \pm 0.8$ \\
\hline BNAB & 0 & 0 & 1.7 & 3.4 & 3.5 & 7.4 & $23.9 \pm 0.4$ & $21.6 \pm 0.5$ & $-11.4 \pm 2.4$ \\
\hline BRMN & 0.5 & 0.5 & 2.1 & 1.5 & 1.5 & 3.4 & $28.1 \pm 0.2$ & $22.2 \pm 0.2$ & $0.8 \pm 0.6$ \\
\hline BSOF & 0.6 & 0.6 & 2.4 & 2.1 & 2.0 & 6.3 & $31.4 \pm 0.2$ & $20.6 \pm 0.2$ & $1.6 \pm 0.5$ \\
\hline BZGN & 0.7 & 0.6 & 2.4 & 2.3 & 2.2 & 5.4 & $31.6 \pm 0.4$ & $17.7 \pm 0.3$ & $0.4 \pm 0.8$ \\
\hline GGSH & 0.5 & 0.6 & 0 & 2.1 & 1.8 & 14.5 & $30.7 \pm 0.3$ & $23.4 \pm 0.2$ & $-80.9 \pm 10.6$ \\
\hline HSTD & 0.5 & 0.5 & 2.2 & 2.0 & 2.1 & 6.6 & $25.8 \pm 0.2$ & $23.6 \pm 0.2$ & $0.9 \pm 0.7$ \\
\hline KBLG & 0.7 & 0.7 & 2.7 & 2.6 & 2.5 & 4.7 & $30.9 \pm 0.4$ & $20.6 \pm 0.4$ & $-0.9 \pm 0.8$ \\
\hline KHJE & 0.5 & 0.5 & 2.3 & 2.4 & 2.1 & 4.7 & $29.6 \pm 0.3$ & $20.0 \pm 0.3$ & $-0.8 \pm 0.7$ \\
\hline KKDY & 0.9 & 0.9 & 3.4 & 3.4 & 2.1 & 5.0 & $31.1 \pm 0.8$ & $18.7 \pm 0.5$ & $1.6 \pm 1.3$ \\
\hline KLBR & 0.9 & 0.7 & 2.8 & 2.8 & 3.2 & 6.6 & $32.1 \pm 0.3$ & $22.6 \pm 0.3$ & $1.4 \pm 0.6$ \\
\hline MMKN & 0.9 & 0.3 & 2.1 & 3.3 & 3.2 & 5.2 & $24.4 \pm 0.5$ & $24.0 \pm 1.8$ & $-1.1 \pm 0.8$ \\
\hline MNDB & 0.9 & 0.6 & 2.3 & 2.0 & 2.6 & 6.1 & $24.3 \pm 0.3$ & $23.4 \pm 0.3$ & $-7.2 \pm 0.8$ \\
\hline NZSF & 0.4 & 0.4 & 2.1 & 2.4 & 2.6 & 4.2 & $31.4 \pm 0.3$ & $20.1 \pm 0.3$ & $0.2 \pm 0.5$ \\
\hline ORYH & 0.6 & 0.5 & 1.3 & 3.0 & 2.6 & 12.5 & $25.6 \pm 0.4$ & $26.2 \pm 0.3$ & $-50.6 \pm 14.9$ \\
\hline POLD & 0.5 & 0.5 & 2.4 & 1.8 & 2.2 & 5.6 & $31.4 \pm 0.2$ & $19.7 \pm 0.2$ & $1.2 \pm 0.6$ \\
\hline SKOH & 0.5 & 0.5 & 1.9 & 1.5 & 1.7 & 4.5 & $26.7 \pm 0.2$ & $22.4 \pm 0.2$ & $0.8 \pm 0.5$ \\
\hline TABZ & 0.4 & 0.4 & 1.5 & 1.4 & 1.7 & 3.6 & $29.0 \pm 0.3$ & $20.4 \pm 0.3$ & $3.8 \pm 0.7$ \\
\hline TASJ & 0.5 & 0.5 & 2.1 & 1.5 & 1.6 & 5.7 & $27.00 \pm 0.1$ & $24.1 \pm 0.1$ & $1.4 \pm 0.4$ \\
\hline TKCE & 0.4 & 0.4 & 2.1 & 2.8 & 2.4 & 5.9 & $26.7 \pm 0.3$ & $22.1 \pm 0.2$ & $1.4 \pm 0.6$ \\
\hline VLDN & 0.6 & 0.7 & 2.7 & 1.8 & 2.2 & 5.0 & $29.3 \pm 0.2$ & $23.6 \pm 0.2$ & $1.0 \pm 0.5$ \\
\hline YKKZ & 0.6 & 0.6 & 2.2 & 2.1 & 2.2 & 5.1 & $31.0 \pm 0.2$ & $20.9 \pm 0.2$ & $1.2 \pm 0.5$ \\
\hline ZARI & 0.8 & 0.8 & 2.9 & 1.8 & 2.2 & 4.7 & $26.2 \pm 0.2$ & $24.4 \pm 0.3$ & $0.4 \pm 0.7$ \\
\hline
\end{tabular}

Table 4. White noise amplitude $(a(m m))$, flicker noise amplitude $\left(b_{-1}\left(m m / \mathrm{yr}^{1 / 4}\right)\right)$, and estimated reliable velocities together with their realistic uncertainties $\left(v \pm \sigma_{v}(\mathrm{~mm} / \mathrm{yr})\right)$ for the three components. 
Based on our evaluations, the realistic uncertainties at the east, north, and up components are 5.0, 4.8, and 4.4 times greater than the optimistic uncertainties, respectively, which represent agreement with previous studies. According to the findings of Yuan et al. [2007], the realistic uncertainties are 2 to 6 times larger than the optimistic uncertainties. In the up component, Teferle et al. [2008] have reported that the realistic uncertainty is 3 to 4 times larger than the optimistic uncertainty, while Santamaria-Gomez et al. [2011] have reported the factor of 4 to 5 . It is worth mentioning that the definition of the stochastic model slightly changes the velocities by the average rate of $0.45,0.53$, and $0.86 \mathrm{~mm} / \mathrm{yr}$ at the east, north, and up components, respectively.

The average uncertainties of the east, north, and up components are $0.28,0.33$, and $1.70 \mathrm{~mm} / \mathrm{yr}$, respectively, indicating that the velocity uncertainty at the up component is substantially higher than those of the horizontal components. The velocity uncertainty of the up component ranges from $0.4 \mathrm{~mm} / \mathrm{yr}$ at the TASJ station to 14.9 $\mathrm{mm} / \mathrm{yr}$ at the ORYH station. From Table 4, we find that the vertical velocities of some stations (ARDH, BZGN, NZSF, and ZARI) are smaller than their realistic uncertainties, which means that they should be excluded from the geodetic and geophysical studies. It is worth noting that, considering the optimistic uncertainties derived from only the white noise, the vertical velocities of the aforementioned stations become significant implying the necessity of the noise analysis. In other words, the realistic uncertainties grant reliable geophysical or geodynamic interpretations [Bogusz et al., 2019].

Figure 5 depicts the horizontal and vertical velocity vectors for the stations in the northwest network of Iran. As illustrated in Figure 5a, these stations virtually have the same horizontal velocities. The average horizontal velocity obtained from Table 4 is $36.0 \pm 0.3 \mathrm{~mm} / \mathrm{yr}$ at the azimuth of $52.66^{\circ} \mathrm{NE}$. Figure $5 \mathrm{~b}$ demonstrates that the GGSH, ORYH, BNAB and MNDB stations possess completely different vertical velocities compared to the other stations. The subsidence of these stations is estimated to be more than $7 \mathrm{~mm} / \mathrm{yr}$, while the vertical velocities of the other stations are in the range of -5 to $5 \mathrm{~mm} / \mathrm{yr}$.

To evaluate our results, we compare our estimated velocities with those obtained from Median Interannual Difference Adjusted for Skewness (MIDAS) [Blewitt et al., 2018]. For this purpose, we use seven MIDAS stations that are close to our network and their time span is approximately consistent with this study. The velocities of these stations along with their uncertainties are listed in Table 5 [Blewitt et al., 2018]. For each MIDAS station, the nearest station of our network is selected and the velocity difference between these two stations is calculated. Note that the nearest station of our network to the ISER station is MNDB, while the rest of MIDAS stations are close to ARDH. Figure 6 depicts the velocity difference between MIDAS and our network stations. From Figure 6, we find that, except for the north component of the HAKK station, our results are consistent with the MIDAS results. It is worth mentioning that according to Table 5, the velocity of the HAKK station in the north component $(9.04 \mathrm{~mm} / \mathrm{yr}$ ) seems abnormal compared to its neighboring MIDAS stations. The small differences observed in results can be attributed to the methodological differences, time span (especially at the ISER and MRDY stations), and the distance between the stations.

\begin{tabular}{cccccccc} 
station & $\begin{array}{c}\text { latitude } \\
(\mathbf{d e g})\end{array}$ & $\begin{array}{c}\text { longitude } \\
(\mathbf{d e g})\end{array}$ & start date & end date & $\begin{array}{c}\boldsymbol{v}_{E} \pm \sigma_{v_{E}} \\
(\mathbf{m m} / \mathbf{y r})\end{array}$ & $\begin{array}{c}v_{N} \pm \sigma_{v_{N}} \\
(\mathbf{m m} / \mathbf{y r})\end{array}$ & $\begin{array}{c}v_{U} \pm \sigma_{v_{U}} \\
(\mathbf{m m} / \mathbf{y r})\end{array}$ \\
\hline BASK & 38.04 & 44.02 & 2009 & 2016 & $22.27 \pm 0.30$ & $26.70 \pm 0.42$ & $0.38 \pm 1.28$ \\
\hline CAT9 & 38.01 & 43.06 & 2009 & 2016 & $22.87 \pm 0.34$ & $26.80 \pm 0.54$ & $-0.61 \pm 1.27$ \\
\hline HAKK & 37.57 & 43.74 & 2009 & 2016 & $26.42 \pm 0.34$ & $9.04 \pm 0.37$ & $1.85 \pm 1.24$ \\
\hline ISER & 36.16 & 44.01 & 2009 & 2020 & $22.62 \pm 0.21$ & $26.07 \pm 0.29$ & $-7.95 \pm 0.78$ \\
\hline MRDY & 38.99 & 43.76 & 2009 & 2014 & $27.41 \pm 0.73$ & $18.40 \pm 0.67$ & $0.73 \pm 1.41$ \\
\hline OZAL & 38.66 & 43.99 & 2009 & 2016 & $24.50 \pm 0.25$ & $25.97 \pm 0.30$ & $0.12 \pm 0.90$ \\
\hline SEMD & 37.31 & 44.57 & 2009 & 2016 & $22.07 \pm 0.36$ & $25.18 \pm 0.32$ & $1.11 \pm 1.30$ \\
\hline
\end{tabular}

Table 5. MIDAS velocities and uncertainties [Blewitt et al., 2018] of stations close to the northwest network of Iran as well as their location and time span. 
Seyed Amin Ghasemi Khalkhali et al.
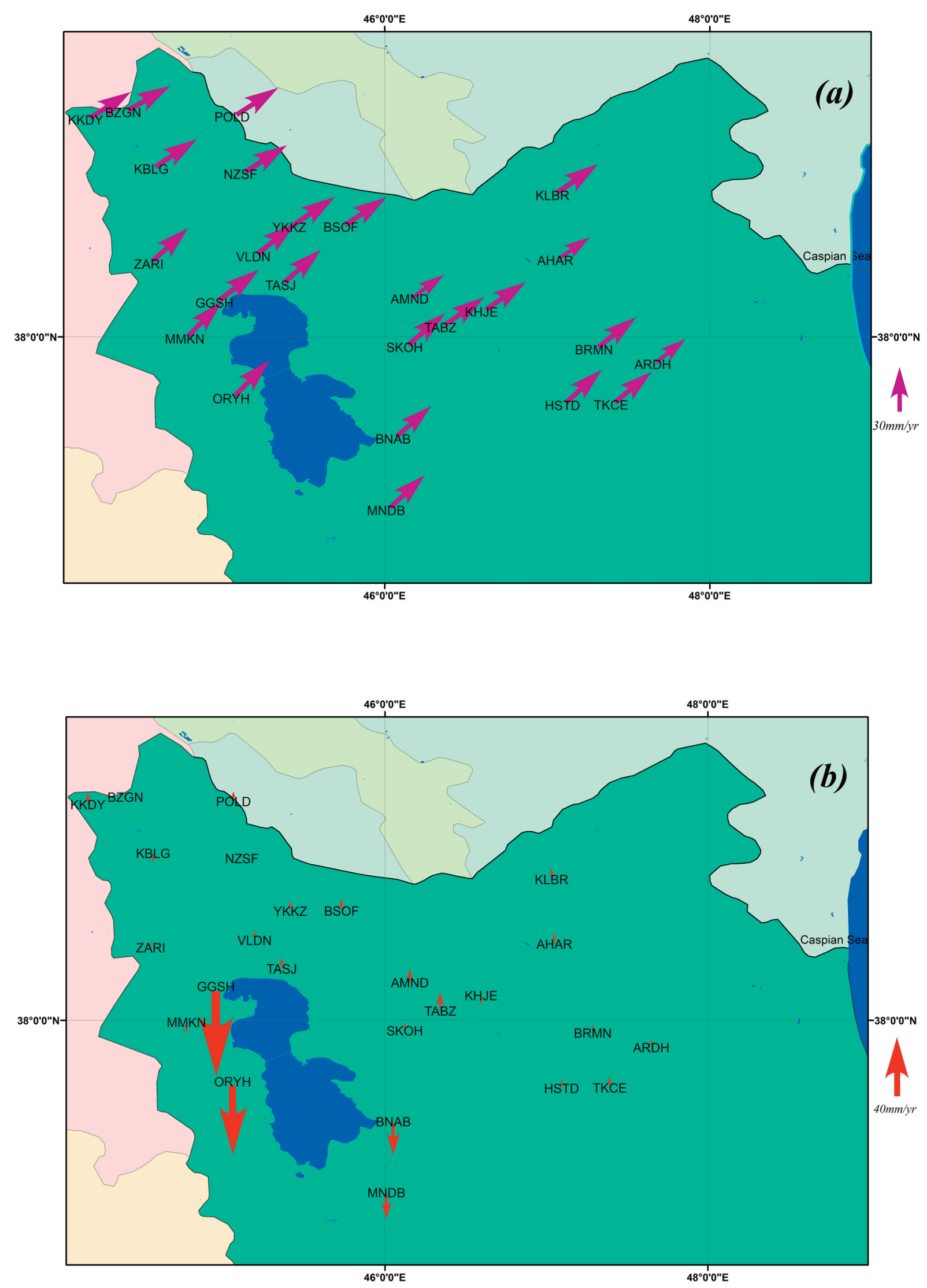

Figure 5. The horizontal (a) and vertical (b) velocity vectors of the stations in the northwest network of Iran. 


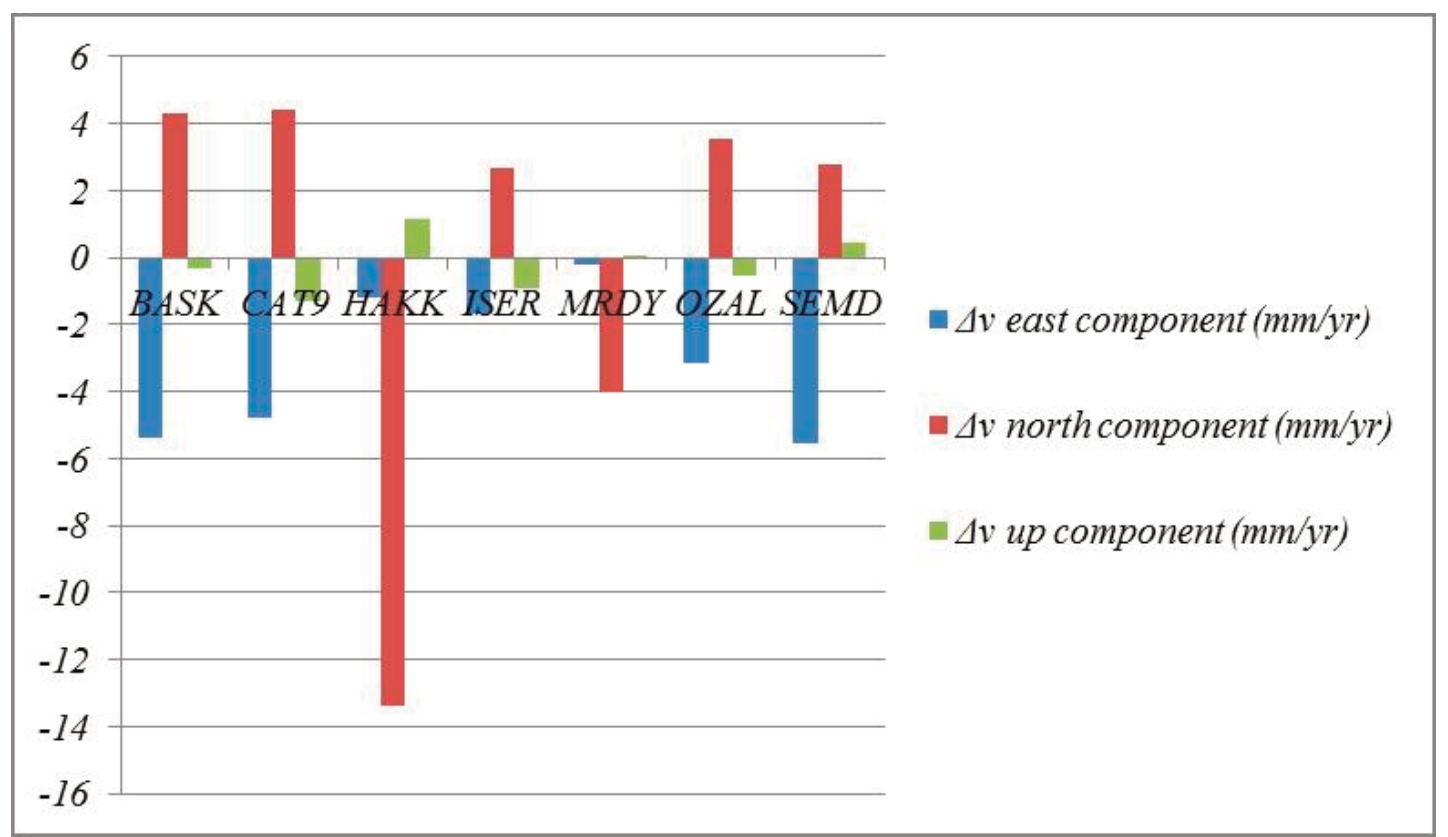

Figure 6. The velocity difference $(\Delta v)$ between the MIDAS stations and the nearest station of northwest network of Iran at three coordinate components.

As a by-product of the time series analysis, we study the periodic signals of the stations. Having the coefficients of $s_{P}$ and $c_{P}$ in Eq. (2), the corresponding amplitude of the periodic component, $A_{P}$, can be computed from the following formula:

$$
A_{P}=\sqrt{s_{p}^{2}+c_{p}^{2}}
$$

Figure 7 presents the amplitudes of the periodic components for all three coordinate components at all stations. The median values of these amplitudes are given in Table 6. In Figure 7 and Table 6, the amplitudes of $A_{1}$ to $A_{4}$ are related to the annual, semi-annual, draconitic year, and second draconitic harmonic signals, respectively. The results show that the amplitudes of the vertical component are significantly larger than those of the horizontal components, which is in agreement with the findings of Klos and Bogusz, [2017] and Klos et al. [2018]. Moreover, we find that, overall, the largest amplitudes are related to the annual and draconitic year signals, as reported by Bogusz and Klos [2016].

\begin{tabular}{ccccc} 
& $\boldsymbol{A}_{\mathbf{1}}(\mathbf{m m})$ & $\boldsymbol{A}_{\mathbf{2}}(\mathbf{m m})$ & $\boldsymbol{A}_{\mathbf{3}}(\mathbf{m m})$ & $\boldsymbol{A}_{\mathbf{4}}(\mathbf{m m})$ \\
\hline east & 0.63 & 0.21 & 0.81 & 0.18 \\
\hline north & 0.73 & 0.26 & 0.88 & 0.44 \\
\hline up & 4.21 & 1.25 & 1.64 & 0.53 \\
\hline
\end{tabular}

Table 6. The median of amplitudes of periodic signals for the east, north, and up components. The amplitudes of $A_{1}$ to $A_{4}$ are related to the annual, semi-annual, draconitic year, and second draconitic harmonic signals, respectively.

It is worth mentioning that the GGSH, ORYH, and BNAB stations, which are in the proximity of Lake Urmia, have generally the largest amplitudes. Furthermore, these stations have the largest vertical velocities (Figure $5 \mathrm{~b}$ ) as well as the nonlinear trend in the up component. This may be due to the hydrological behavior of Lake Urmia and its basin. As a matter of fact, because of the drought in 2007 [Trigo et al., 2010] and the increase of groundwater extraction in this region, the mean groundwater level has been decreased considerably. Forootan et al. [2014] have indicated that the groundwater storage in the Lake Urmia region changes by $-11.2 \mathrm{~mm} / \mathrm{yr}$ based on GRACE product from 2005 


\section{Seyed Amin Ghasemi Khalkhali et al.}

to 2011; see also Hosseini-Moghari et al. [2020]. According to the findings of Tourian et al. [2015], the lake's water level and its area has been decreased at an average rate of $34 \pm 1 \mathrm{~cm} / \mathrm{yr}$ and $220 \pm 6 \mathrm{~km}^{2} / \mathrm{yr}$ between 2002 to 2014 , respectively. These hydrological behaviors over Lake Urmia and its basin lead to anomalous subsidence in this region, which may cause abnormal effects observed in these three stations adjacent to Lake Urmia.
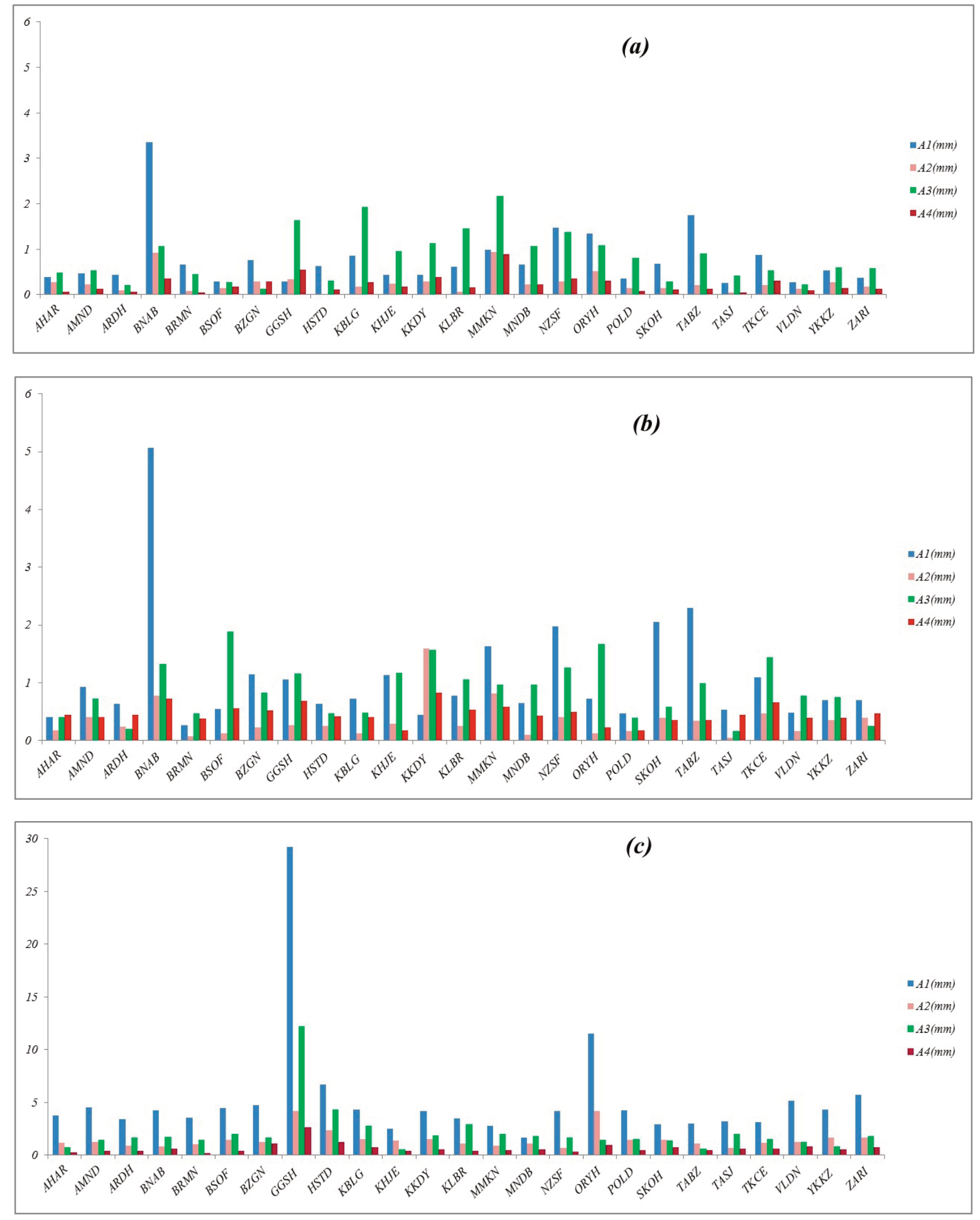

Figure 7. The amplitudes of periodic signals for (a) east, (b) north, and (c) up components. The amplitudes of to are related to the annual, semi-annual, draconitic year, and second draconitic harmonic signals, respectively. 


\section{Conclusion}

In this study, the daily position time series of 25 permanent GNSS stations in the northwest network of Iran from 2006 to 2016 were analyzed to enhance the estimation of the station motion parameters, and particularly to determine reliable velocity vectors together with their realistic uncertainties. For this purpose, a comprehensive computation was developed on two integrated parts, namely, the deterministic model analysis and noise analysis. To the best of our knowledge, no time series analysis has been conducted in this area; therefore, the results of our study will remarkably contribute to the further geophysical studies.

In the deterministic model analysis part, in an iterative process, real jumps are identified, due to co-seismic displacements or to changing of the instruments. In addition, the best functional model is obtained for the station motion trend as well as the post-seismic deformation. From the results, we found that most stations have a linear trend. However, in the BNAB, GGSH, ORYH, and MMKN stations, a nonlinear trend is observed in at least one of their components. Moreover, we found that a combination of logarithmic and exponential functions is optimal model for post-seismic deformation in this area.

Results indicate that in the spatial filtering step, the norm of post-fit residual vector is reduced by $19.34 \%$, $17.51 \%$ and $12.44 \%$ at the east, north and up components, respectively. Concerning the stochastic model, we found that the noise of the up component is significantly higher than the noise of the other components. We observed that the white and flicker noise amplitudes in the vertical component are 3.7 times and 2.7 times the horizontal components, respectively. According to our findings, the realistic uncertainties at the east, north, and up components are 5.0, 4.8, and 4.4 times greater than the optimistic uncertainties, respectively.

We estimated the vertical velocity of most stations to be in the range of -5 to $5 \mathrm{~mm} / \mathrm{yr}$, except for three stations that are in the proximity of Lake Urmia. We also found that these three stations have distinctive features such as nonlinear trend, large periodic signal and anomalous subsidence, which may be due to the hydrological behavior over Lake Urmia and its basin. We observed that the network stations move horizontally with a velocity of $36.0 \pm$ $0.3 \mathrm{~mm} / \mathrm{yr}$ on average. The azimuth of this motion is $52.66^{\circ} \mathrm{NE}$. The estimated parameters of periodic signal of the stations demonstrate that the amplitude of periodic signals of the up component is significantly larger than that of the east and north components. Moreover, the annual and draconitic year signals have the largest amplitudes in the three coordinate components.

Acknowledgments. We would like to thank the National Cartographic Center (NCC) of Iran and the Iranian Seismological Center (IRSC) for providing the data required for this study. We would also like to thank the anonymous reviewers for their valuable and constructive comments which helped us to improve the paper.

\section{References}

Agnew, D. C. (1992). The time-domain behavior of power-law noises, Geophys. Res. Lett., 19, 4, 333-336.

Allahverdi-Zadeh, A., J. Asgari and A. Amiri-Simkooei (2016). Investigation of GPS draconitic year effect on GPS time series of eliminated eclipsing GPS satellite data, J. Geodetic Sci., 6, 1.

Altamimi, Z., P. Rebischung, L. Métivier and X. Collilieux (2016). ITRF2014: A new release of the International Terrestrial Reference Frame modeling nonlinear station motions, J. Geophys. Res., Solid Earth, 121(8), 61096131.

Amiri-Simkooei, A. (2009). Noise in multivariate GPS position time-series, J. Geodesy, 83, 2, 175-187.

Amiri-Simkooei, A. (2016). Non-negative least-squares variance component estimation with application to GPS time series, J. Geodesy, 90(5), 451-466.

Amiri-Simkooei, A., M. Hosseini-Asl, J. Asgari and F. Zangeneh-Nejad (2019). Offset detection in GPS position time series using multivariate analysis, GPS solutions, 23, 1, 13.

Amiri-Simkooei, A., T. Mohammadloo and D. Argus (2017). Multivariate analysis of GPS position time series of JPL second reprocessing campaign, J. Geodesy, 91, 6, 685-704.

Amiri-Simkooei, A. (2013). On the nature of GPS draconitic year periodic pattern in multivariate position time series, J. Geophys. Res., Solid Earth, 118, 5, 2500-2511. 


\section{Seyed Amin Ghasemi Khalkhali et al.}

Amiri-Simkooei, A., C. Tiberius and S. P. Teunissen, (2007). Assessment of noise in GPS coordinate time series: methodology and results, J. Geophys. Res., Solid Earth, 112(B7).

Argus, D. F., W. Peltier, R. Drummond and A. W.Moore (2014). The Antarctica component of postglacial rebound model ICE-6G_C (VM5a) based on GPS positioning, exposure age dating of ice thicknesses, and relative sea level histories, Geophys. J. Int., 198, 1, 537-563.

Barzaghi, R. and A. Borghi (2018). Theory of second order stationary random processes applied to GPS coordinate time-series, GPS Solutions, 22, 3, 86 .

Borghi, A., A. Aoudia, F. Javed and R. Barzaghi (2016). Precursory slow-slip loaded the 2009 L'Aquila earthquake sequence, Geophys. J. Int., 205, 2, 776-784.

Borghi, A., A. Aoudia, R. E Riva and R. Barzaghi (2009). GPS monitoring and earthquake prediction: a success story towards a useful integration, Tectonophysics, 465, 1-4, 177-189.

Borghi, A., L. Cannizzaro and A. Vitti (2012). Advanced techniques for discontinuity detection in GNSS coordinate time-series, An Italian case study, Geodesy for Planet Earth, Springer, 627-634.

Bevis, M., and A. Brown (2014). Trajectory models and reference frames for crustal motion geodesy, J. Geodesy, 88, 3, 283-311. .

Birhanu, Y., S. Williams, R. Bendick and S. Fisseha (2018). Time dependence of noise characteristics in continuous GPS observations from East Africa, J. African Earth Sci., 144, 83-89.

Blewitt, G. and D. Lavallée (2002). Effect of annual signals on geodetic velocity, J. Geophys. Res., Solid Earth, 107, B7, ETG 9-1-ETG 9-11.

Blewitt, G., W. C. Hammond and C. Kreemer (2018). Harnessing the GPS data explosion for interdisciplinary science, Eos, 99, 1-2.

Bock, Y., R. M.Nikolaidis, P. J. de Jonge and M. Bevis (2000). Instantaneous geodetic positioning at medium distances with the Global Positioning System, J. Geophys. Res., Solid Earth, 105(B12), 28223-28253.

Bogusz, J., M. Gruszczynski, M. Figurski and A. Klos (2015). Spatio-temporal filtering for determination of common mode error in regional GNSS networks. Open Geosciences, 7, 1, doi:10.1515/geo-2015-0021

Bogusz, J. and A. Klos, (2016). On the significance of periodic signals in noise analysis of GPS station coordinates time series, GPS solutions, 20, 4, 655-664.

Bogusz, J., Klos, A., M. Gruszczynska and M. Gruszczynski (2016). Towards reliable velocities of permanent GNSS stations, Reports on Geodesy and Geoinformatics, 100, 1, 17-26.

Bogusz, J., A. Klos and K. Pokonieczny (2019). Optimal Strategy of a GPS Position Time Series Analysis for PostGlacial Rebound Investigation in Europe, Remote Sensing, 11, 10, 1209.

Bogusz, J., and B. Kontny (2011). Estimation of sub-diurnal noise level in GPS time series, Acta Geodynamica et Geomaterialia, 8, 3, 163.

Bruni, S., S. Zerbini, F. Raicich, M. Errico and E. Santi (2014). Detecting discontinuities in GNSS coordinate time series with STARS: case study, the Bologna and Medicina GPS sites, J. Geodesy, 88, 12, 1203-1214.

Burgmann, R., S. Ergintav, P. Segall, E. H. Hearn, S. McClusky, R. E. Reilinger, H. Woith,

and J. Zschau (2002). Time-dependent distributed afterslip on and deep below the Izmit earthquake rupture, Bull. Seismol. Soc. Am., 92, 1, 126-137.

Calais, E. (1999). Continuous GPS measurements across the Western Alps, 1996-1998, Geophys. J. Int., 138(1), 221230.

Davis, J. L., B. P.Wernicke and M. E.Tamisiea (2012). On seasonal signals in geodetic time series, J. Geophys. Res., Solid Earth, 117, B1.

Djamour, Y., P. Vernant, H. R.Nankali and F. Tavakoli (2011). NW Iran-eastern Turkey present-day kinematics: results from the Iranian permanent GPS network, Earth Planet. Sci. Lett., 307, 1-2, 27-34.

Dong, D., P. Fang, Y. Bock, M. Cheng and S. i. Miyazaki (2002). Anatomy of apparent seasonal variations from GPS-derived site position time series, J. Geophys. Res., Solid Earth, 107, B4, ETG 9-1-ETG 9-16.

Dong, D., P. Fang, Y. Bock, F. Webb, F., L. Prawirodirdjo, S. Kedar, and P. Jamason (2006). Spatiotemporal filtering using principal component analysis and Karhunen-Loeve expansion approaches for regional GPS network analysis, J. Geophys. Res., Solid Earth, 111, B3.

Forootan, E., R. Rietbroek, J. Kusche, M. A. Sharifi, J. L. Awange, M. Schmidt., P. Omondi and J. Famiglietti (2014). Separation of large scale water storage patterns over Iran using GRACE, altimetry and hydrological data, Remote Sens. Environ., 140, 580-595. 
Gazeaux, J., Williams, S., King, M., Bos, M., Dach, R., Deo, M., A. W. Moore, L. Ostini, E. Petrie, M. Roggero, F. E Teferle, J. Olivares, F. H. Webb (2013). Detecting offsets in GPS time series: First results from the detection of offsets in GPS experiment, J. Geophys. Res., Solid Earth, 118, 5, 2397-2407.

Goudarzi, M. A., M. Cocard, R. Santerre and T. Woldai (2013). GPS interactive time series analysis software, GPS solutions, 17, 4, 595-603.

Graham, S. E., J. P Loveless and B. J. Meade, (2018). Global plate motions and earthquake cycle effects, Geochem., Geophys., Geosyst., 19, 7., 2032-2048.

Gruszczynski, M., A. Klos and J. Bogusz, (2016). Orthogonal transformation in extracting of common mode errors from continuous GPS networks, Acta Geodynamica et Geomaterialia, 13, 3, 291-298.

Gruszczynski, M., A. Klos and J. Bogusz (2018). A filtering of incomplete GNSS position time series with probabilistic principal component analysis, Pure Appl. Geophys., 175, 1841-1867.

Hackl, M., R. Malservisi, U. Hugentobler and R. Wonnacott (2011). Estimation of velocity uncertainties from GPS time series: Examples from the analysis of the South African TrigNet network, J. Geophys. Res., Solid Earth, 116, B11.

He, X., X. Hua, K. Yu, W. Xuan, T. Lu, W. Zhang and X. Chen (2015). Accuracy enhancement of GPS time series using principal component analysis and block spatial filtering, Adv. Space Res., 55, 5, 1316-1327.

He, X., J.-P. Montillet, R. Fernandes, M. Bos, K. Yu, X. Hua and W. Jiang (2017). Review of current GPS methodologies for producing accurate time series and their error sources, J. Geodyn., 106, 12-29.

Herring, T., R. King and S. McClusky (2015). Introduction to GAMIT/GLOBK, release 10.6, Mass. Inst. of Technol., Cambridge.

Hosseini-Moghari, S.-M., S. Araghinejad, M. J. Tourian, K. Ebrahimi and P. Döll (2020). Quantifying the impacts of human water use and climate variations on recent drying of Lake Urmia basin: the value of different sets of spaceborne and in situ data for calibrating a global hydrological model, Hydrol. Earth Sys. Sci., 24(4).

Itoh, Y. and T. Nishimura (2016). Characteristics of postseismic deformation following the 2003 Tokachi-oki earthquake and estimation of the viscoelastic structure in Hokkaido, northern Japan, Earth, Planets and Space, $68,1,156$.

Jiang, W., J. Ma, Z. Li, X. Zhou and B. Zhou (2018). Effect of removing the common mode errors on linear regression analysis of noise amplitudes in position time series of a regional GPS network and a case study of GPS stations in Southern California, Adv. Space Res., 61, 10, 2521-2530.

Khorrami, F., P. Vernant, F. Masson, F. Nilfouroushan, Z. Mousavi, H. Nankali, R. Saadat, A. Walpersdorf, S. Hosseini, P. Tavakoli, A. Aghamohammadi, M. Alijanzade. (2019). An up-to-date crustal deformation map of Iran using integrated campaign-mode and permanent GPS velocities, Geophys. J. Int., 217, 2, 832-843.

King, N., J. Svarc, E. Fogleman, W. Gross, K. Clark, G. Hamilton, C. H Stiffler, J. Sutton (1995). Continuous GPS observations across the Hayward fault, California, 1991-1994. J. Geophys. Res., Solid Earth, 100(B10), 2027120283.

King, M. A. and C. S. Watson (2010). Long GPS coordinate time series: multipath and geometry effects. J. Geophys. Res., Solid Earth, 115, B4.

King, M. A. and S. D.Williams (2009). Apparent stability of GPS monumentation from short-baseline time series. J. Geophys. Res., Solid Earth, 114, B10.

Klos, A. and J. Bogusz (2017). An evaluation of velocity estimates with a correlated noise: case study of IGS ITRF2014 European stations, Acta Geodynamica et Geomaterialia, 14, 3, 255-265.

Klos, A., M. S. Bos and J. Bogusz (2018). Detecting time-varying seasonal signal in GPS position time series with different noise levels, GPS solutions, 22, 1, 21.

Klos, A., G. Olivares, F. N. Teferle, A. Hunegnaw and J. Bogusz (2018). On the combined effect of periodic signals and colored noise on velocity uncertainties, GPS solutions, 22, 1, 1.

Klos, A., J. Kusche, L. Fenoglio-Marc, M. S. Bos, and J. Bogusz (2019). Introducing a vertical land motion model for improving estimates of sea level rates derived from tide gauge records affected by earthquakes, GPS Solutions, $23,4,102$.

Kogan, M. G. and G. M.Steblov (2008). Current global plate kinematics from GPS (1995-2007) with the plate-consistent reference frame, J. Geophys. Res., Solid Earth, 113, B4.

Langbein, J. (2004). Noise in two-color electronic distance meter measurements revisited, J. Geophys. Res., Solid Earth, 109, B4.

Langbein, J. (2008). Noise in GPS displacement measurements from Southern California and Southern Nevada. J. 


\section{Seyed Amin Ghasemi Khalkhali et al.}

Geophys. Res., Solid Earth, 113, B5.

Langbein, J. and Y. Bock (2004). High-rate real-time GPS network at Parkfield: Utility for detecting fault slip and seismic displacements, Geophys. Res. Lett., 31, 15.

Langbein, J. and H. Johnson (1997). Correlated errors in geodetic time series: Implications for time-dependent deformation, J. Geophys. Res., Solid Earth, 10, B1, 591-603.

Larson, K. M. and T. van Dam (2000). Measuring postglacial rebound with GPS and absolute gravity, Geophys. Res. Lett., 27, 23, 3925-3928.

Li, W., W. Jiang, Z. Li, H. Chen, Q. Chen, J. Wang, and G. Zhu (2020). Extracting Common Mode Errors of Regional GNSS Position Time Series in the Presence of Missing Data by Variational Bayesian Principal Component Analysis, Sensors, 20, 8, 2298.

Li, W., F. Li, S. Zhang, J. Lei, Q. Zhang and L. Yuan (2019). Spatiotemporal Filtering and Noise Analysis for Regional GNSS Network in Antarctica Using Independent Component Analysis. Remote Sensing, 11, 4, 386.

Liu, B., W. Dai, W. Peng and X. Meng (2015). Spatiotemporal analysis of GPS time series in vertical direction using independent component analysis, Earth, Planets and Space, 67, 1, 189.

Mao, A., C. G. Harrison, and T. H. Dixon (1999). Noise in GPS coordinate time series, J. Geophys. Res., Solid Earth, 104, B2, 2797-2816.

Márquez-Azúa, B. and C. DeMets (2003). Crustal velocity field of Mexico from continuous GPS measurements, 1993 to June 2001: Implications for the neotectonics of Mexico, J. Geophys. Res., Solid Earth, 108, B9.

Masson, F., M. Anvari, Y. Djamour, A. Walpersdorf, A., F. Tavakoli, M. Daignieres, H. Nankali, S. Van Gorp (2007). Large-scale velocity field and strain tensor in Iran inferred from GPS measurements: new insight for the present-day deformation pattern within NE Iran, Geophys. J. Int., 170, 1, 436-440.

Masson, F., Y. Djamour, S. Van Gorp, J. Chéry, M. Tatar, F. Tavakoli, H. Nankali, P. Vernant (2006). Extension in NW Iran driven by the motion of the South Caspian Basin, Earth Planet. Sci. Lett., 252, 1-2, 180-188.

Montillet, J.-P., S. Williams, A. Koulali, and S. McClusky (2015). Estimation of offsets in GPS time-series and application to the detection of earthquake deformation in the far-field, Geophys. J. Int., 200, 2, 1207-1221.

Nikolaidis, R. (2004). Observation of geodetic and seismic deformation with the Global Positioning System, Thesis.

Nilforoushan, F., F. Masson, P. Vernant, C. Vigny, J. Martinod, M. Abbassi, H. Nankali, D. Hatzfeld, R. Bayer, F. Tavakoli, A. Ashtiani, E. Doerflinger, M. Daignières, P. Collard, J. Chéry (2003). GPS network monitors the Arabia-Eurasia collision deformation in Iran. J. Geodesy, 77, 7-8, 411-422.

Nocquet, J. M., E. Calais and B. Parsons (2005). Geodetic constraints on glacial isostatic adjustment in Europe. Geophys. Res. Lett., 32, 6.

Ostanciaux, E., L. Husson, G. Choblet, C. Robin and K. Pedoja (2012). Present-day trends of vertical ground motion along the coast lines, Earth-Sci. Rev., 110, 1-4, 74-92.

Press, W. H., S. A.Teukolsky, B. P. Flannery and W. T.Vetterling (1992). Numerical recipes in Fortran 77: volume 1, volume 1 of Fortran numerical recipes: the art of scientific computing, Cambridge university press.

Ray, J., Z. Altamimi, X. Collilieux and T. van Dam (2008). Anomalous harmonics in the spectra of GPS position estimates, GPS solutions, 12, 1, 55-64.

Riley, W. (2008). Algorithms for frequency jump detection, Metrologia, 45, 6, S154.

Rizza, M., P. Vernant, J.-F. Ritz, M. Peyret, H. Nankali, H. Nazari, Y. Djamour, R. Salamati, F. Tavakoli, J. Chéry, S. A. Mahan, F. Masson (2013). Morphotectonic and geodetic evidence for a constant slip-rate over the last $45 \mathrm{kyr}$ along the Tabriz fault (Iran), Geophys. J. Int., 193, 3, 1083-1094.

Santamaría-Gómez, A., M. N. Bouin, X. Collilieux, and G. Wöppelmann (2011). Correlated errors in GPS position time series: Implications for velocity estimates, J. Geophys. Res., Solid Earth, 116, B1.

Sella, G. F., S. Stein, T. H. Dixon, M. Craymer, T. S. James, S. Mazzotti and R. K. Dokka (2007). Observation of glacial isostatic adjustment in "stable” North America with GPS, Geophys. Res. Lett., 34, 2.

Tan, W., J. Chen, D. Dong, W. Qu and X. Xu (2020). Analysis of the Potential Contributors to Common Mode Error in Chuandian Region of China, Remote Sensing, 12, 5, 751.

Teferle, F. N., S. D Williams, H. P. Kierulf, R. M. Bingley and H.-P. Plag (2008). A continuous GPS coordinate time series analysis strategy for high-accuracy vertical land movements, Phys. Chem. Earth, Parts A/B/C, 33, 3-4, 205-216.

Tobita, M. (2016). Combined logarithmic and exponential function model for fitting postseismic GNSS time series after 2011 Tohoku-Oki earthquake, Earth, Planets and Space, 68, 1, 1-12. 
Tourian, M., O. Elmi, Q. Chen, B. Devaraju, S. Roohi, and N. Sneeuw (2015). A spaceborne multisensor approach to monitor the desiccation of Lake Urmia in Iran, Remote Sensing Environ., 156, 349-360.

Trigo, R. M., C. M. Gouveia and D. Barriopedro (2010). The intense 2007-2009 drought in the Fertile Crescent: Impacts and associated atmospheric circulation, Agricultural and Forest Meteorology, 150, 6, 1245-1257.

Vernant, P., F. Nilforoushan, D. Hatzfeld, M. Abbassi, C. Vigny, F. Masson, H. Nankali, J. Martinod, A. Ashtiani, R. Bayer, F. Tavakoli, J. Chéry (2004). Present-day crustal deformation and plate kinematics in the Middle East constrained by GPS measurements in Iran and northern Oman, Geophys. J. Int., 157, 1, 381-398.

Wang, W., B. Zhao, Q. Wang and S. Yang (2012). Noise analysis of continuous GPS coordinate time series for CMONOC, Adv. Space Res., 49,5, 943-956.

Wdowinski, S., Y. Bock, G. Baer, L. Prawirodirdjo, N. Bechor, S. Naaman, R. Knafo, Y. Forrai, Y. Melzer (2004). GPS measurements of current crustal movements along the Dead Sea Fault, J. Geophys. Res., Solid Earth, 109, B5.

Wdowinski, S., Y. Bock, J. Zhang, P. Fang and J. Genrich (1997). Southern California permanent GPS geodetic array: Spatial filtering of daily positions for estimating coseismic and postseismic displacements induced by the 1992 Landers earthquake, J. Geophys. Res., Solid Earth, 102, B8, 18057-18070.

Williams, S. (2003). The effect of coloured noise on the uncertainties of rates estimated from geodetic time series, J. Geodesy, 76, 9-10, 483-494.

Williams, S. D. (2003). Offsets in global positioning system time series, J. Geophys. Res., Solid Earth, 108, B6.

Williams, S. D., Y. Bock, P. Fang, P. Jamason, R. M. Nikolaidis, L. Prawirodirdjo, M. Miller, D. J. Johnson (2004). Error analysis of continuous GPS position time series, J. Geophys. Res., Solid Earth, 109, B3.

Wu, S., G. Nie, J. Liu, K. Wang, C. Xue, J. Wang, C. Xue, J. Wang, H. Li, F. Peng, X. Ren (2019). A Sub-Regional Extraction Method of Common Mode Components from IGS and CMONOC Stations in China. Remote Sensing, 11(11), 1389.

Yuan, L., X. Ding, S. Kwok and R. Chan (2007). Statistic analysis of daily position time series from the Hong Kong local dense GPS network. Paper presented at the The International Global Navigation Satellite Systems Society (IGNSS) Symposium 2007.

Zhang, J., Y. Bock, H. Johnson, P. Fang, S. Williams, J. Genrich, S. Wdowinski, J. Behr (1997). Southern California Permanent GPS Geodetic Array: Error analysis of daily position estimates and site velocities, J. Geophys. Res., Solid Earth, 102, B8, 18035-18055.

Zhu, Z., X. Zhou, L. Deng, K. Wang and B. Zhou (2017). Quantitative analysis of geophysical sources of common mode component in CMONOC GPS coordinate time series, Adv. Space Res., 60, 12, 2896-2909. 